\title{
Microstructural Evolution in CuCrFeNi, CuCrFeNiMn, and CuCrFeNiMnAl High Entropy Alloys
}

\author{
Jae Ik Hyun, Kyeong Ho Kong, Kang Cheol Kim, Won Tae Kim , Do Hyang Kim* \\ Center for Non-crystalline Materials, Department of Materials Science and Engineering, Yonsei University, Seoul 120-749, Korea \\ ${ }^{1}$ Department of Optical Engineering, Cheongju University, Cheongju 363-764, Korea
}

*Correspondence to:

$\mathrm{Kim} \mathrm{DH}$,

Tel: +82-2-2123-4254

Fax: +82-2-312-8281

E-mail: dohkim@yonsei.ac.kr

Received March 13, 2015

Revised March 23, 2015

Accepted March 23, 2015

\begin{abstract}
In the present study, microstructural evolution in $\mathrm{CuCrFeNi}, \mathrm{CuCrFeNiMn}$, and $\mathrm{CuCrFeNiMnAl}$ alloys has been investigated. The as-cast $\mathrm{CuCrFeNi}$ alloy consists of a single fcc phase with the lattice parameter of $0.358 \mathrm{~nm}$, while the as-cast $\mathrm{CuCrFeNiMn}$ alloy consists of $(\mathrm{bcc}+\mathrm{fcc} 1+\mathrm{fcc} 2)$ phases with lattice parameters of $0.287 \mathrm{~nm}, 0.366 \mathrm{~nm}$, and $0.361 \mathrm{~nm}$. The heat treatment of the cast $\mathrm{CuCrFeNiMn}$ alloy results in the different type of microstructure depending on the heat treatment temperature. At $900^{\circ} \mathrm{C}$ a new thermodynamically stable phase appears instead of the bcc solid solution phase, while at $1,000^{\circ} \mathrm{C}$, the heat treated microstructure is almost same as that in the as-cast state. The addition of $\mathrm{Al}$ in $\mathrm{CuCrFeNiMn}$ alloy changes the constituent phases from $(\mathrm{fcc} 1+\mathrm{fcc} 2+\mathrm{bcc})$ to $(\mathrm{bcc} 1+\mathrm{bcc} 2)$.
\end{abstract}

Key Words: High entropy alloy, CuCrFeNi alloy, fcc solid solution, bcc solid solution, Heat treatment

\section{INTRODUCTION}

Recently, multi-component equiatomic alloys, which is also referred to as high entropy alloys in the literature, receive a great attention as a new type of materials (Cantor et al., 2004; Yeh et al., 2004; Tong et al., 2005b; Tung et al., 2007; Lin \& Tsai, 2011). They are defined as a solid solution of five or more elements, and the amount of each element is ideally balanced, i.e., from 5 to 35 at $\%$ in the case of five elements. Besides the high entropy due to near-equal atomic content in the multi-component system, another requirement for the definition of high entropy alloys is the small difference in atomic radii of the constituent elements (Yang \& Zhang, 2012). It has been shown that the high-entropy alloys exhibit high mixing entropy, lattice distortion, sluggish diffusion and cocktail effect. They provide high-entropy alloys with a wide spectrum of microstructure and properties, indicating that these alloys have great potentials in many applications such as tools, molds, dies and mechanical parts (Yeh et al., 2004).
It has been postulated that, when the number of alloying elements is more than five, the contribution of configurational entropy to the total free energy becomes high enough to overcome the enthalpies for intermetallic compound formation. Therefore, the single solid solution state becomes stable, replacing multi-phase microstructures (Yeh et al., 2004). In contrast to high entropy alloys, low-entropy alloys refer to the alloys based on one principal metallic element, and medium-entropy alloys refer to the alloys based on two to four principal elements (Yeh et al., 2007). In such multicomponent alloys, it is obvious that the configurational entropy reaches maximum when the amount of each alloying element is equal (Yeh et al., 2004). Consequently, the main emphasis for the high-entropy alloy research has been placed on the alloys consisting of multiple principal elements with ideally equal proportions.

Although the concept mentioned above can predict the formation of a single phase solid solution in some multicomponent systems, most of the high entropy alloys reported

This work was supported by the Global Research Laboratory Program of the Korean Ministry of Education, Science and Technology.

@ This is an open-access article distributed under the terms of the Creative Commons Attribution Non-Commercial License (http://creativecommons.org/licenses/by-nc/3.0) which permits unrestricted noncommercial use, distribution, and reproduction in any medium, provided the original work is properly cited.

Copyrights (c) 2015 by Korean Society of Microscopy 
Hyun Jl et al.

so far consists of more than one solid solution phases or contain other intermetallic phases (Huang et al., 2004; Tong et al., 2005a, 2005b; Wang et al., 2007; Yeh et al., 2007; Zhou et al., 2007; Wang \& Zhang, 2008; Shun et al., 2010; Zhu et al., 2010). The difficulty in formation of a single phase solid solution can be understood from the reason that driving force for phase stability such as enthalpy and non-configurational entropy usually overwhelms the configurational entropy, destabilizing the formation of a single phase solid solution. For example, the equi-atomic $\mathrm{CrMnFeCoNi}$ alloy which was first reported by Cantor et al. (2004) consists of a fcc single solid solution phase. Therefore, it can be summarized that alloying elements such as $\mathrm{Cu}, \mathrm{Ni}, \mathrm{Mn}$, and Co prefer to the formation of a fcc single phase, while alloying elements such as $\mathrm{Al}, \mathrm{Cr}, \mathrm{W}, \mathrm{V}$, and Ti prefer to the formation of a bcc single phase.

The as-cast equi-atomic AlCoCrCuFeNi alloy is known to exhibit superior thermomechanical properties high hardness and compressive strength, and high thermal stability at high temperature (Tong et al., 2005a; Yeh et al., 2007). However, the microstructure reported in the literature was not consistent: it has been reported that in the as-cast $\mathrm{AlCoCrCuFeNi}$ alloy with equi-atomic composition, the $\mathrm{Cu}, \mathrm{Co}$, and $\mathrm{Ni}$ elements prefer to the formation of a fcc solid solution phase, while $\mathrm{Al}$ and $\mathrm{Cr}$ favors the formation of a bcc solid solution phase which significantly enhance the hardness of these alloys (Tung et al., 2007), or the alloy consists of Al-Ni- and Cr-Ferich phases with bcc structures. Here, the Al-Ni-rich phase is an ordered phase of B2 type and the Cr-Fe-rich phase is a disordered phase (Singh et al., 2011).

The microstructure of the equi-atomic CuCrFeNiMn alloy has been investigated in detail since it consists of a fcc single solid solution phase (Ren et al., 2010). It was also found that the alloys with higher $\mathrm{Ni}$ equivalent mainly consist of a single fcc phase, and those with a higher $\mathrm{Cr}$ equivalent are mainly composed of fcc+bcc mixed structures. The effect of aging treatment on the hardness and microstructure of the CuCrFeNiMn alloy has been investigated (Ren et al., 2012). Through aging treatment, the alloy exhibits a significantly improved hardness level of $450 \mathrm{HV}$ at $800^{\circ} \mathrm{C}$, which results from precipitation hardening and homogenization of the microstructure.

In the present study, fcc single phase forming elements $\mathrm{Cu}, \mathrm{Mn}$ and $\mathrm{Ni}$ and bcc single phase forming element $\mathrm{Al}$ and $\mathrm{Cr}$ were selected to form $\mathrm{CuCrFeNi}, \mathrm{CuCrFeNiMn}$, and $\mathrm{CuCrFeNiMnAl}$ alloy systems. Three aspects in the microstructure evolution in these alloy systems have been investigated in the present study: 1) microstructure evolution in as-cast $\mathrm{CuCrFeNi}$ and $\mathrm{CuCrFeNiMn}$ alloy systems; 2) effect of heat treatment on the microstructure evolution in CuCrFeNiMn alloy system; and 3) effect of addition of $\mathrm{Al}$ with equi-atomic content on the microstructure evolution in
CuCrFeNiMn alloy system.

\section{MATERIALS AND METHODS}

$\mathrm{CuCrFeNi}$, CuCrFeNiMn, and CuCrFeNiMnAl alloy ingots were alloyed from high-purity elements using arc melting in water-cooled molds under argon atmosphere. The ingots were re-melted at least three times to improve their chemical homogeneity. The nominal chemical compositions are listed in Table 1. To investigate the effect of cooling rate on the microstructure evolution, the alloy ingots were remelted, and poured into the conical cylinder-type mold. The microstructure of the specimens cut at the at the diameters of 6 and $12 \mathrm{~mm}$ were compared after polishing and etching. The specimens were observed under a scanning electron microscope (SEM, JSM-7001F; JEOL, Japan). The chemical composition of the phases in these alloys was analyzed by energy dispersive spectrometry (EDS, 51-ADD0069; Oxford Instruments, UK) assembled in SEM. X-ray diffractometer (XRD, Ultima IV; Rigaku, Japan) with $\mathrm{Cu} \mathrm{K}_{\alpha}$ radiation for a $2 \theta$ range of $20^{\circ}$ to $80^{\circ}$ at a speed of $4^{\circ} / \mathrm{min}$ was used for identification of the crystalline structures in the alloys. Detailed microstructural investigations were carried out with a transmission electron microscope (TEM, JEM-2100F; JEOL). The TEM samples were prepared by using an ion milling equipment (PIPS, Model 691; Gatan, USA).

\section{RESULTS AND DISCUSSION}

\section{Microstructure Evolution in As-cast CuCrFeNi and CuCrFeNiMn Alloy Systems}

Fig. 1 compares the XRD patterns obtained from the as-cast $\mathrm{CuCrFeNi}$ and $\mathrm{CuCrFeNiMn}$ alloys. The diffraction peaks from the as-cast $\mathrm{CuCrFeNi}$ alloy were identified as a single fcc phase with the lattice parameter of $0.358 \mathrm{~nm}$, while those from the as-cast $\mathrm{CuCrFeNiMn}$ alloy were identified as a mixture of fcc and bcc phases. The lattice parameter of the bcc phase was $0.287 \mathrm{~nm}$, while that of the fcc phase could not be determined unanimously due to the double peaks at the position of the diffraction peaks of the fcc structure. Fig. 2 compares the SEM images obtained from the as-cast $\mathrm{CuCrFeNi}$ and $\mathrm{CuCrFeNiMn}$ alloys together with the EDS results obtained from the constituent phases in the alloys. It can be noticed that the as-cast $\mathrm{CuCrFeNi}$ alloy (Fig. 2A) consists of a coarse

Table 1. Composition of the alloys investigated in the present study (at\%)

\begin{tabular}{lcllllc}
\hline \multicolumn{1}{c}{ Alloy } & $\mathrm{Al}$ & $\mathrm{Cu}$ & $\mathrm{Cr}$ & $\mathrm{Fe}$ & $\mathrm{Ni}$ & $\mathrm{Mn}$ \\
\hline CuCrFeNi & - & 25 & 25 & 25 & 25 & - \\
CuCrFeNiMn & - & 20 & 20 & 20 & 20 & 20 \\
CuCrFeNiMnAl & 16.7 & 16.7 & 16.7 & 16.7 & 16.7 & 16.7 \\
\hline
\end{tabular}


dendritic phase with a small fraction of an interdendritic phase. The composition of the dendritic phase was $26.6 \% \mathrm{Cr}$ $29.0 \% \mathrm{Fe}-27.4 \% \mathrm{Ni}-17.0 \% \mathrm{Cu}$, and that of the interdendritic phase was 3.8\% Cr-6.3\% Fe-5.7\% Ni-84.2\% Cu (hereafter, the composition is in at\%). Considering the XRD result in Fig. 1, the dendritic phase was the fcc solid solution phase. However, the interdendritic phase was highly concentrated with $\mathrm{Cu}$. It is noteworthy that much higher content of $\mathrm{Cr}$ was present in the fcc phase than in the interdendritic phase, since Cr prefers to the formation of the bcc single phase. It is not clear in the present study why $\mathrm{Cr}$ is enriched in the dendritic phase, while $\mathrm{Cu}$ is highly enriched in the interdendritic region. On the

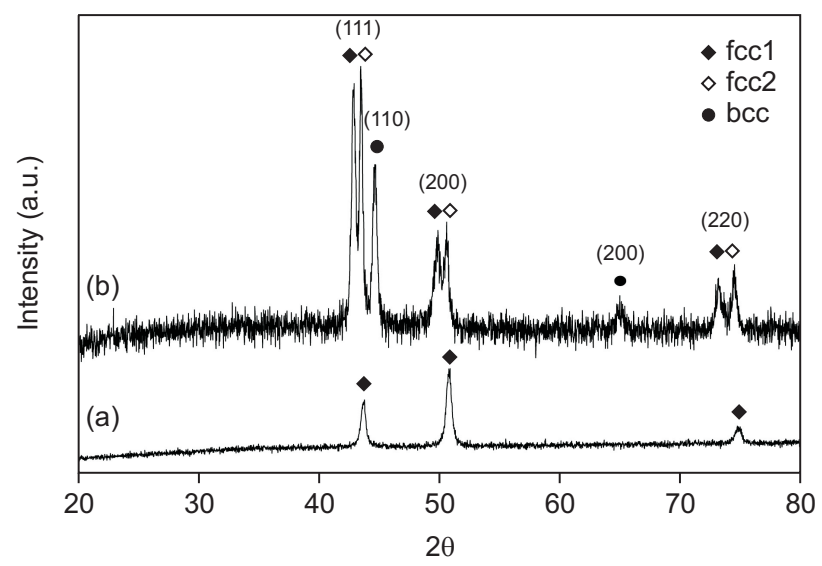

Fig. 1. X-ray diffractometer patterns obtained from the as-cast $\mathrm{CuCrFeNi}$ (a) and CuCrFeNiMn (b) alloys. other hand, the as-cast $\mathrm{CuCrFeNiMn}$ alloy exhibited a very much different microstructure (Fig. 2B). The microstructure consisted of three different regions with light, gray and dark contrast as marked as 1,2, and 3 in Fig. 2B. The EDS results showed that the compositions of light, gray and dark contrast regions were 4.8\% $\mathrm{Cr}-24.5 \% \mathrm{Mn}-7.2 \% \mathrm{Fe}-17.9 \% \mathrm{Ni}-45.6 \%$ $\mathrm{Cu}, 21.0 \% \mathrm{Cr}-16.4 \% \mathrm{Mn}-27.4 \% \mathrm{Fe}-25.8 \% \mathrm{Ni}-9.4 \% \mathrm{Cu}$, and $38.2 \% \mathrm{Cr}-13.5 \% \mathrm{Mn}-29.9 \% \mathrm{Fe}-14.0 \% \mathrm{Ni}-4.5 \% \mathrm{Cu}$, respectively, indicating that light and gray contrast phases marked as 1 and 2 corresponded to the fcc phase, and dark contrast phase marked as 3 corresponded to the bcc phase. It can be noticed that two different fcc phases are present with a large composition difference: fcc phase marked 1 enriched in $\mathrm{Cu}$ and $\mathrm{Mn}$; and fcc phase marked as 2 enriched in $\mathrm{Fe}, \mathrm{Ni}$, and Cr.

TEM analysis was performed in order to investigate in more detail on the microstructural characterisitics of the $\mathrm{CuCrFeNiMn}$ alloy which exhibit double diffraction peaks from the fcc phase. Fig. 3A shows the bright field (BF) TEM micrograph obtained from the as-cast $\mathrm{CuCrFeNiMn}$ alloy. The BF TEM image shows three grains marked as 1, 2, and 3 in Fig. 3A. The composition measured from the BF TEM image is also included. The composition of the grains marked as 1, 2, and 3 corresponded to $7.2 \% \mathrm{Cr}-23.5 \% \mathrm{Mn}-$ 8.5\% Fe-19.8\% Ni-41.0\% Cu, 23.9\% Cr-15.2\% Mn-26.6\% Fe-24.2\% Ni-10.1\% Cu, and 43.1\% Cr-11.3\% Mn-29.2\% Fe-11.5\% Ni-4.8\% Cu, which are almost same as shown in the SEM image (Fig. 2B). Fig. 3B and C shows selected area diffraction patterns (SADPs) obtained from the grain 1 and 2,
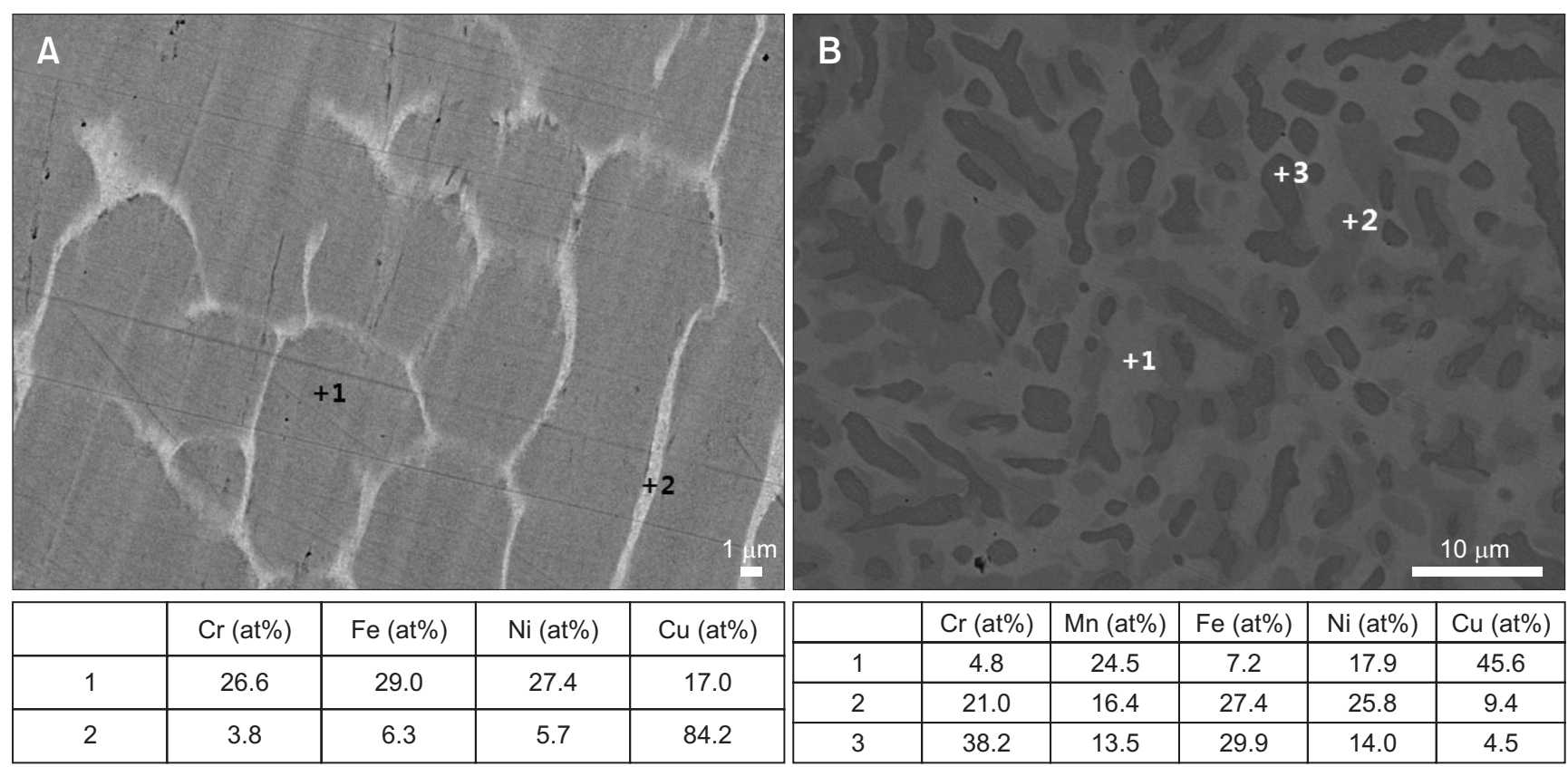

Fig. 2. Scanning electron microscope images obtained from the as-cast $\mathrm{CuCrFeNi}$ (A) and CuCrFeNiMn (B) alloys together with the energy dispersive spectrometry result from the constituent phases. 


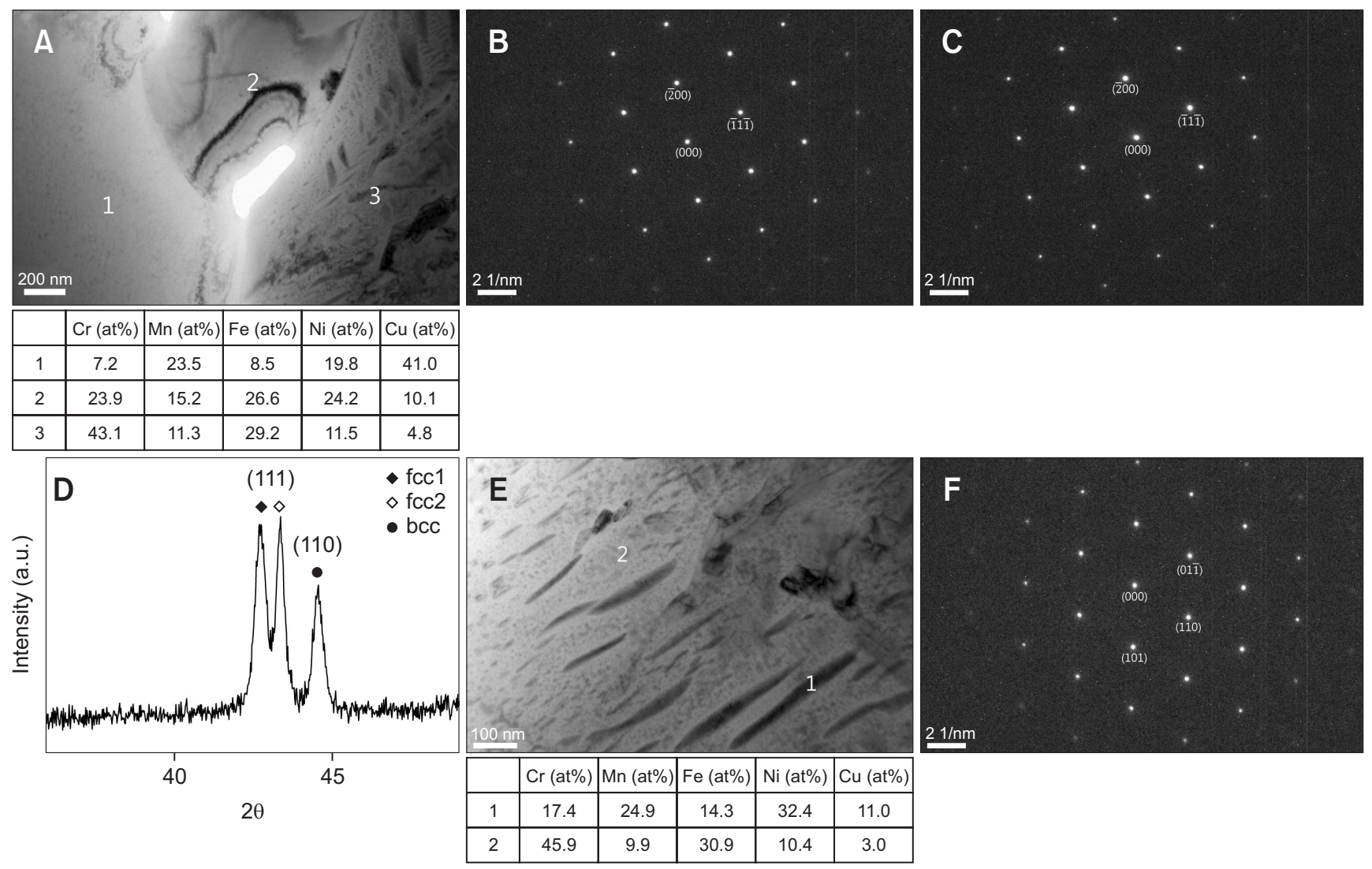

Fig. 3. (A) Bright field transmission electron microscope (BF TEM) micrograph obtained from the as-cast CuCrFeNiMn alloy together with the compositions from each grain marked 1,2, and 3. (B, C) Selected area diffraction patterns (SADPs) obtained from grain 1 and 3, respectively. (D) Identification of the X-ray diffractometer pattern shown in Fig. 1(b). (E) Magnified BF TEM image obtained from the grain marked as 3 in Fig. 3A together with the energy dispersive spectrometry result. (F) SADP taken from the area marked as 2 in Fig. 3E.

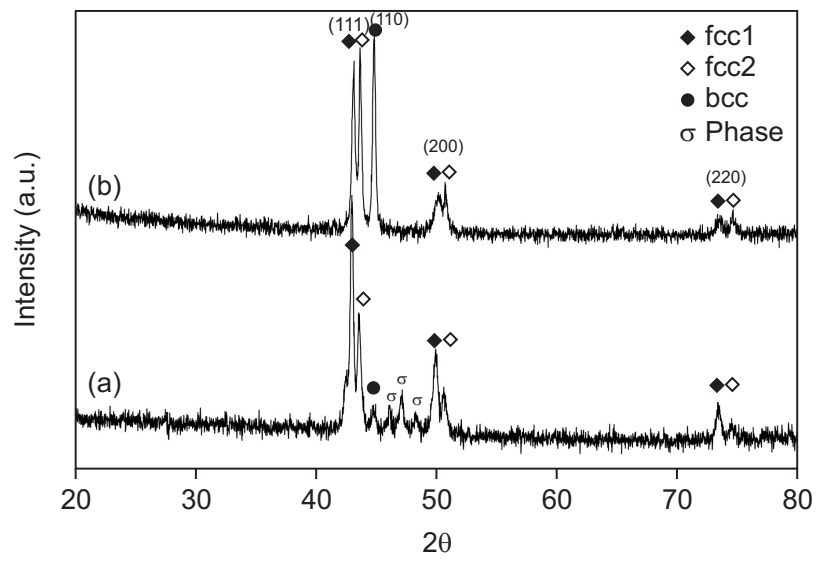

Fig. 4. X-ray diffractometer pattern obtained from the cast $\mathrm{CuCrFeNiMn}$ alloy after heat treatment for 48 hours at $900^{\circ} \mathrm{C}$ (a) and $1,000^{\circ} \mathrm{C}(\mathrm{b})$.

respectively. The two SADPs were indexed as same [011] zone of the fcc structure; however, the distance between the spots was slightly different. For example, there was $1.55 \%$ difference in the distance between (000) and (111), indicating that two fcc phase with different lattice parameter (fccl: $0.366 \mathrm{~nm}$, fcc2: $0.361 \mathrm{~nm}$ ). Therefore, the XRD pattern shown in Fig. 1(b) can be indexed as shown in Fig. 3D. Fig. 3E shows the magnified BF TEM image obtained from the grain marked as 2 in Fig. 3A. As shown in the EDS result, the composition of the area marked as 1 in Fig. 3E was 17.4\% Cr-24.9\% Mn$14.3 \% \mathrm{Fe}-32.4 \% \mathrm{Ni}-11.0 \% \mathrm{Cu}$, while that of the area marked as 2 was $45.9 \% \mathrm{Cr}-9.9 \% \mathrm{Mn}-30.9 \% \mathrm{Fe}-10.4 \% \mathrm{Ni}-3.0 \% \mathrm{Cu}$, indicating that the rod-shaped fcc phase is embedded in the bcc phase matrix. The SADP taken from the area marked as 2 in Fig. 3E which was indexed as [111] zone.

\section{Effect of Heat Treatment on the Microstructure Evolution in CuCrFeNiMn Alloy System}

Based on the thermal analysis result on the $\mathrm{CuCrFeNiMn}$ alloy, heat treatment was performed at $900^{\circ} \mathrm{C}$ and $1,000^{\circ} \mathrm{C}$ for 48 hours. Fig. 4 shows the XRD pattern obtained from the cast $\mathrm{CuCrFeNiMn}$ alloy after heat treatment at $900^{\circ} \mathrm{C}$ and $1,000^{\circ} \mathrm{C}$ for 48 hours. It is interesting to notice that the position and intensity of the diffraction peaks in the sample heat treated at $1,000^{\circ} \mathrm{C}$ are almost identical as in the as-cast sample shown in 

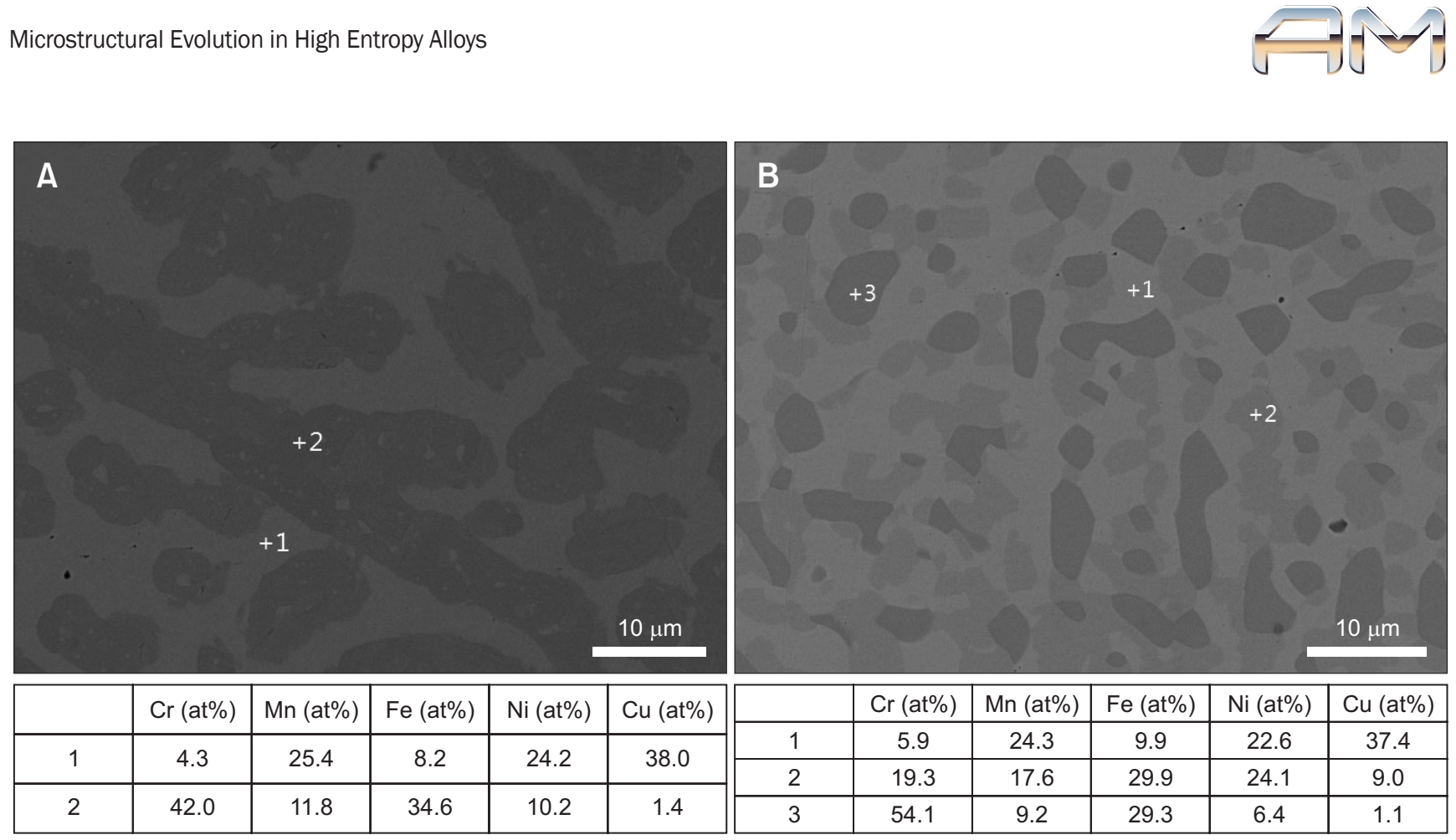

Fig. 5. Scanning electron microscope image obtained from the cast $\mathrm{CuCrFeNiMn}$ alloy after heat treatment for 48 hours at $900^{\circ} \mathrm{C}(\mathrm{A})$ and $1,000^{\circ} \mathrm{C}(\mathrm{B})$.

Fig. 1; however, after heat treatment at $900^{\circ} \mathrm{C}$, the intensity of the diffraction peaks from the bcc phase significantly reduced, and new diffraction peaks which were indexed as $\sigma$ phase appeared. Fig. 5 compares the SEM image obtained from the cast $\mathrm{CuCrFeNiMn}$ alloy after heat treatment at $900^{\circ} \mathrm{C}$ and $1,000^{\circ} \mathrm{C}$ for 48 hours. The SEM image in Fig. $5 \mathrm{~A}$ shows that $\sigma$ phase forms around the dendritic phase by provision of $\mathrm{Cr}$ and Fe from the bcc phase after heat treatment at $900^{\circ} \mathrm{C}$. As a result, $(\mathrm{Cu}, \mathrm{Mn}, \mathrm{Ni})$-rich phase of which the composition is similar to the interdendritic phase. The composition of the area marked as 1 and 2 were $4.3 \% \mathrm{Cr}-25.4 \% \mathrm{Mn}-8.2 \% \mathrm{Fe}-$ $24.2 \% \mathrm{Ni}-38.0 \%$ and $42.0 \% \mathrm{Cr}-11.8 \% \mathrm{Mn}-34.6 \% \mathrm{Fe}-10.2 \%$ $\mathrm{Ni}-1.4 \% \mathrm{Cu}$, respectively. On the other hand, the sample heat treated at $1,000^{\circ} \mathrm{C}$ exhibits almost same microstructure as in the as-cast state shown in Fig. 2. The EDS result also shows same trend as shown in Fig. 2, i.e., the composition of light, gray and dark contrast regions were $5.9 \% \mathrm{Cr}-24.3 \% \mathrm{Mn}-9.9 \%$ $\mathrm{Fe}-22.6 \% \mathrm{Ni}-37.4 \% \mathrm{Cu}, 19.3 \% \mathrm{Cr}-17.6 \% \mathrm{Mn}-29.9 \% \mathrm{Fe}-$ $24.1 \% \mathrm{Ni}-9.0 \% \mathrm{Cu}$ and $54.1 \% \mathrm{Cr}-9.2 \% \mathrm{Mn}-29.3 \% \mathrm{Fe}-6.4 \%$ $\mathrm{Ni}-1.1 \% \mathrm{Cu}$, respectively, conforming the presence of same phases in the as-cast state. As shown in the phase diagram of Fe-Mn-Cu system calculated using Pandat program (Fig. 6), it is expected that the alloy at $1,000^{\circ} \mathrm{C}$ may be at (fcc+liquid) or $(\mathrm{fcc} 1+\mathrm{fcc} 2+$ liquid) phase region, and the liquid may solidified in the bcc or $(\mathrm{bcc}+\mathrm{fcc})$ phase during cooling from $1,000^{\circ} \mathrm{C}$. At $900^{\circ} \mathrm{C}$, the sample is in solid state, and $\sigma$ phase which may be a thermodynamically stable phase at this temperature appears instead of the bcc phase.

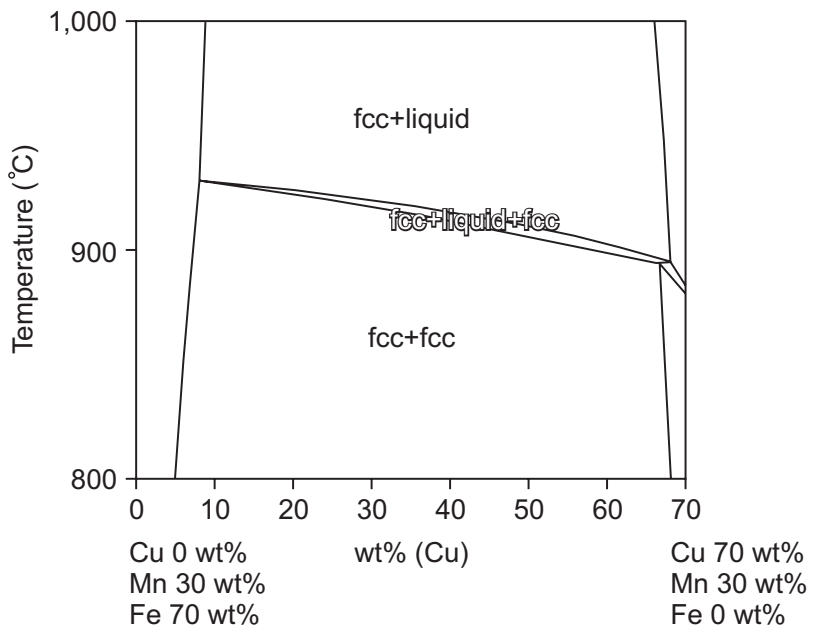

Fig. 6. Fe-Mn-Cu ternary phase diagram using Pandat program.

\section{Effect of Addition of Al with Equi-atomic Content on the Microstructure Evolution in CuCrFeNiMn Alloy System}

Fig. 7 shows the XRD patterns obtained from the ascast $\mathrm{CuCrFeNiMn}$ and $\mathrm{CuCrFeNiMnAl}$ alloys. The XRD patterns shown in Fig. 7(a) and (c) were obtained from the section with $12 \mathrm{~mm}$ diameter (top section), while those shown in Fig. 7(b) and (d) were from the section with $6 \mathrm{~mm}$ diameter (bottom section). As shown in Fig. 1, the as-cast $\mathrm{CuCrFeNiMn}$ alloy consisted of $(\mathrm{fcc} 1+\mathrm{fcc} 2+\mathrm{bcc})$ phases. With addition of equi-atomic content $\mathrm{Al}$, the diffraction peaks from the fcc phases disappeared, indicating that the 
alloy consisted of a single bcc phase. The XRD pattern in Fig. 7(c) and (d) shows that two bcc phases with different lattice parameter (bccl and bcc2) were present in the ascast $\mathrm{Al}$ containing alloy. The result shows that the addition of $\mathrm{Al}$ in $\mathrm{CuCrFeNiMn}$ alloy changes the constituent phases from $(f c c 1+f c c 2+b c c)$ to $(b c c 1+b c c 2)$. Fig. 8 shows the SEM image obtained from the as-cast $\mathrm{CuCrFeNiMnAl}$ alloy together with the EDS result. The microstructure consisted of (dendritic+interdendritic) phases of which the compositions were $10.5 \% \mathrm{Al}-20.9 \% \mathrm{Cr}-15.3 \% \mathrm{Mn}-23.2 \% \mathrm{Fe}-18.0 \% \mathrm{Ni}-$ $12.2 \% \mathrm{Cu}$ and $22.8 \% \mathrm{Al}-3.6 \% \mathrm{Cr}-15.0 \% \mathrm{Mn}-5.6 \% \mathrm{Fe}-20.4 \%$ $\mathrm{Ni}-32.7 \% \mathrm{Cu}$, respectively. Thus the bcc1 phase solidified as primary dendritic phase in the liquid state, and the remaining liquid solidified as bcc2 interdendritic phase during cooling. The primary dendritic phase was more enriched in $\mathrm{Cr}$ and

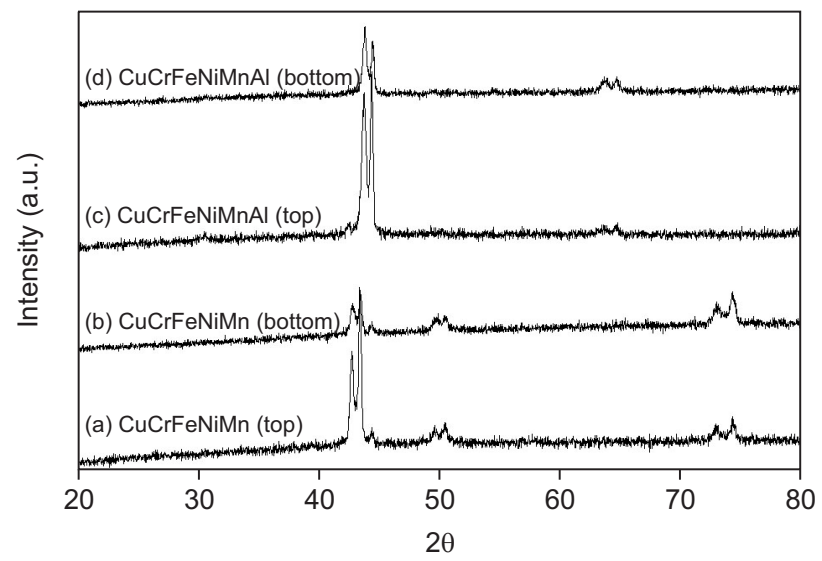

Fig. 7. X-ray diffractometer patterns obtained from the as-cast CuCrFeNiMn (a, b) and CuCrFeNiMnAl (c, d) alloys. (a) and (c) were obtained from the section with $12 \mathrm{~mm}$ diameter (top section), and (b) and (d) were from the section with $6 \mathrm{~mm}$ diameter (bottom section).
$\mathrm{Fe}$, while the interdendritic phase was more enriched in $\mathrm{Al}$ and $\mathrm{Cu}$. In order to investigate the effect of cooling rate, the different sections in the conical cone-type cast alloy were examined. Fig. 9 compares the SEM images obtained from the top ( $6 \mathrm{~mm}$ diameter) and bottom (12 $\mathrm{mm}$ diameter) sections of the $\mathrm{CuCrFeNiMnAl}$ alloy. It can be noticed that there was not much difference in the type of microstructure evolution (primary dendrite+interdendritic). However, as the cooling rate becomes higher, the scale of the (dendritic+interdendritic) microstructure becomes finer without any phase change

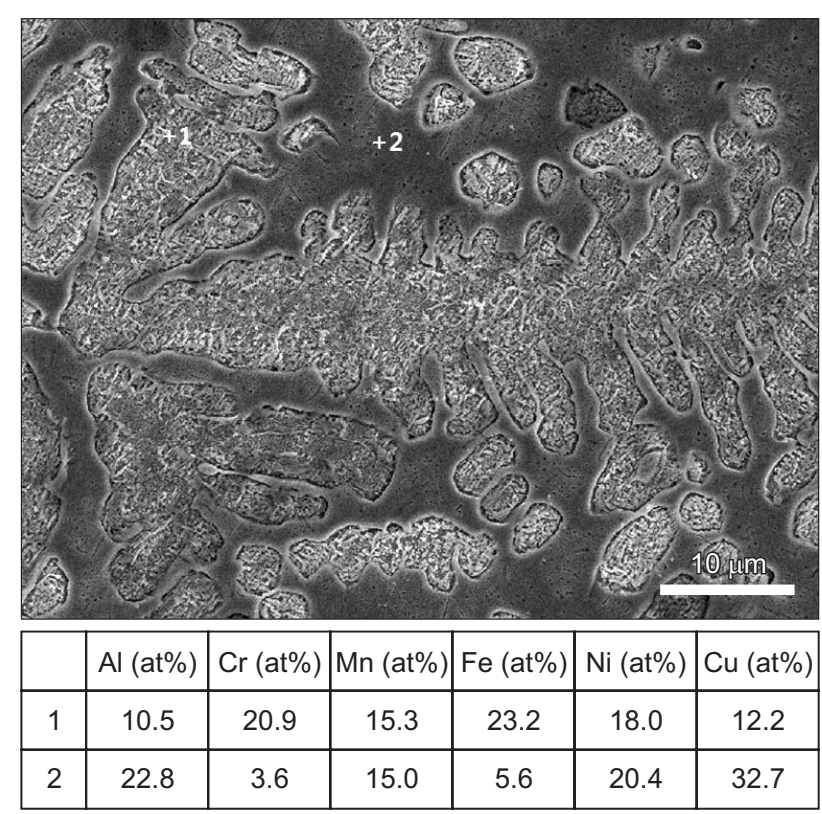

Fig. 8. Scanning electron microscope image obtained from the as-cast CuCrFeNiMnAl alloy together with the energy dispersive spectrometry result.
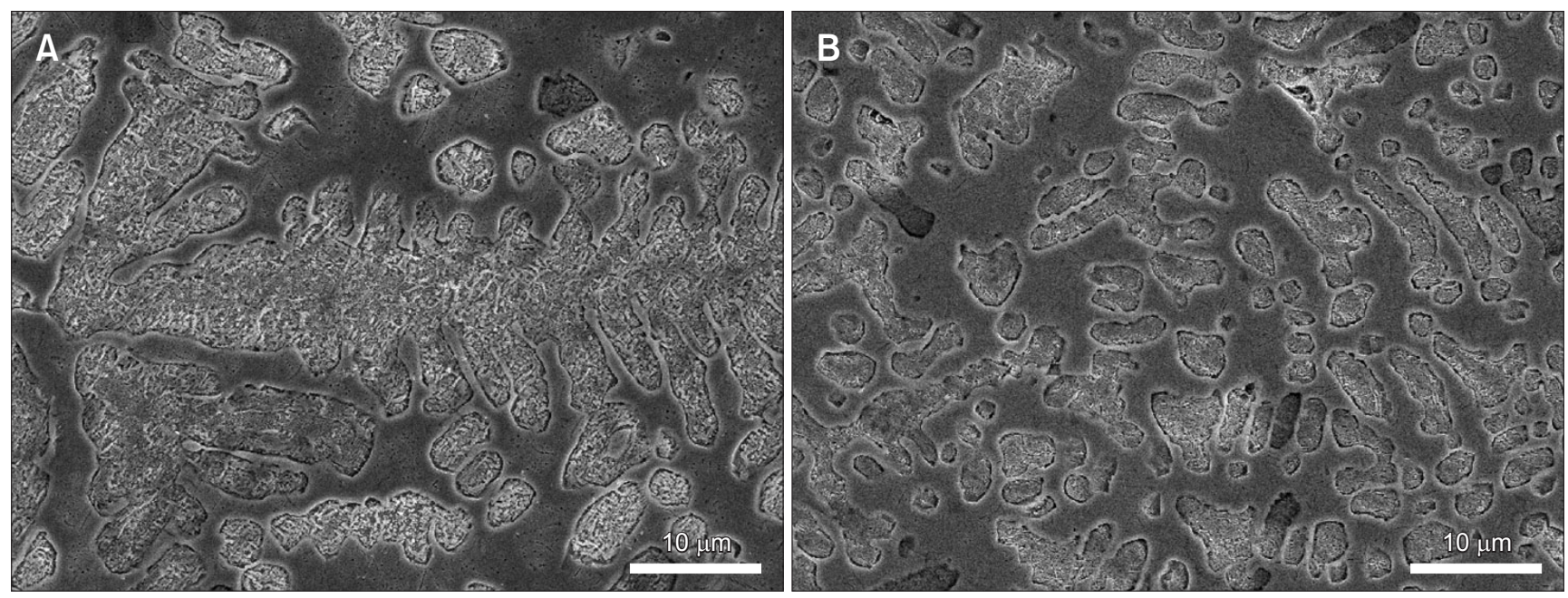

Fig. 9. Scanning electron microscope images obtained from top (A) and bottom (B) sections of the CuCrFeNiMnAl alloy. 
depending on the cooling rate.

\section{CONCLUSIONS}

Microstructural evolution in $\mathrm{CuCrFeNi}, \mathrm{CuCrFeNiMn}$, and $\mathrm{CuCrFeNiMnAl}$ alloys has been investigated in the present study. The main conclusions are as follows: (1) The as-cast $\mathrm{CuCrFeNi}$ alloy consists of a single fcc phase with the lattice parameter of $0.358 \mathrm{~nm}$ and typical composition of $26.6 \% \mathrm{Cr}-29.0 \% \mathrm{Fe}-27.4 \% \mathrm{Ni}-17.0 \% \mathrm{Cu}$. While the ascast $\mathrm{CuCrFeNiMn}$ alloy consists of $(\mathrm{bcc}+\mathrm{fcc} 1+\mathrm{fcc} 2)$ phases with lattice parameters of $0.287 \mathrm{~nm}, 0.366 \mathrm{~nm}$ and 0.361 $\mathrm{nm}$, and with typical compositions of $43.1 \% \mathrm{Cr}-11.3 \% \mathrm{Mn}$ 29.2\% Fe-11.5\% Ni-4.8\% Cu, 7.2\% Cr-23.5\% Mn-8.6\% Fe$19.8 \% \mathrm{Ni}-41.0 \% \mathrm{Cu}$, and $23.9 \% \mathrm{Cr}-15.2 \% \mathrm{Mn}-26.6 \% \mathrm{Fe}-$ $24.2 \% \mathrm{Ni}-10.1 \% \mathrm{Cu}$. (2) The as-cast CuCrFeNi alloy exhibits a fcc solid solution dendritic-type microstructure with highly $\mathrm{Cu}$-enriched interdendritic region. While the as-cast CuCrFeNiMn alloy exhibit bcc dendritic microstructure, but fccl and fcc2 phase are present in the interdendritic region. (3) The heat treatment of the cast CuCrFeNiMn alloy results in the different type of microstructure depending on the heat treatment temperature. The alloy is maintained as solid state during annealing at $900^{\circ} \mathrm{C}$ for 48 hours, and new thermodynamically stable phase appears instead of the bcc solid solution phase. However, after annealing at $1,000^{\circ} \mathrm{C}$ for 48 hours, the microstructure is almost same as that in the as-cast state. (4) The addition of $\mathrm{Al}$ in CuCrFeNiMn alloy changes the constituent phases from $(\mathrm{fcc} 1+\mathrm{fcc} 2+\mathrm{bcc})$ to (bcc1+bcc2) where typical compositions of bcc1 and bcc2 are 10.5\% Al-20.9\% Cr-15.3\% Mn-23.2\% Fe-18.0\% Ni-12.2\% $\mathrm{Cu}$, and $22.8 \% \mathrm{Al}-3.6 \% \mathrm{Cr}-15.0 \% \mathrm{Mn}-5.6 \% \mathrm{Fe}-20.4 \% \mathrm{Ni}-$ $32.7 \% \mathrm{Cu}$, respectively.

\section{CONFLICT OF INTEREST}

No potential conflict of interest relevant to this article was reported.

\section{REFERENCES}

Cantor B, Chang I T H, Knight P, and Vincent A J B (2004) Microstructural development in equiatomic multicomponent alloys. Mater. Sci. Eng. A 375, 213-218.

Huang P K, Yeh J W, Shun T T, and Chen S K (2004) Multi-principalelement alloys with improved oxidation and wear resistance for thermal spray coating. Adv. Eng. Mater. 6, 74-78.

Lin C M and Tsai H L (2011) Evolution of microstructure, hardness, and corrosion properties of high-entropy $\mathrm{Al}(0.5) \mathrm{CoCrFeNi}$ alloy. Intermetallics 19, 288-294.

Ren B, Liu Z X, Cai B, Wang M X, and Shi L (2012) Aging behavior of a CuCr2Fe2NiMn high-entropy alloy. Mater. Design 33, 121-126.

Ren B, Liu Z X, Li D M, Shi L, Cai B, and Wang M X (2010) Effect of elemental interaction on microstructure of CuCrFeNiMn high entropy alloy system. J. Alloys Compd. 493, 148-153.

Shun T T, Hung C H, and Lee C F (2010) Formation of ordered/disordered nanoparticles in FCC high entropy alloys. J. Alloys Compd. 493, 105109.

Singh S, Wanderka N, Murty B S, Glatzel U, and Banhart J (2011) Decomposition in multi- component AlCoCrCuFeNi high-entropy alloy. Acta Mater. 59, 182-190.

Tong C J, Chen M R, Chen S K, Yeh J W, Shun T T, Lin S J, and Chang S Y (2005a) Mechanical performance of the AlxCoCrCuFeNi high-entropy alloy system with multiprincipal elements. Metall. Mater. Trans. A 36, 1263-1271.

Tong C J, Chen Y L, Chen S K, Yeh J W, Shun T T, Tsau C H, Lin S J, and Chang S Y (2005b) Microstructure characterization of AlxCoCrCuFeNi high-entropy alloy system with multiprincipal elements. Metall. Mater. Trans. A 36, 881-893.

Tung C C, Yeh J W, Shun T T, Chen S K, Huang Y S, and Chen H C (2007) On the elemental effect of AlCoCrCuFeNi high-entropy alloy system. Mater. Lett. 61, 1-5.

Wang F J and Zhang Y (2008) Effect of Co addition on crystal structure and mechanical properties of Ti0.5CrFeNiAICo high entropy alloy. Mater. Sci. Eng. A 496, 214-216.

Wang X F, Zhang Y, Qiao Y, and Chen G L (2007) Novel microstructure and properties of multicomponent CoCrCuFeNiTix alloys. Intermetallics 15, 357-362.

Yang $X$ and Zhang Y (2012) Prediction of high-entropy stabilized solidsolution in multi-component alloys. Mater. Chem. Phys. 132, 233238.

Yeh J W, Chen S K, Lin S J, Gan J Y, Chin T S, Shun T T, Tsau C H, and Chang S Y (2004) Nanostructured high-entropy alloys with multiple principal elements: novel alloy design concepts and outcomes. Adv. Eng. Mater. 6, 299-303.

Yeh J W, Chen Y L, Lin S J, and Chen S K (2007) High-entropy alloys-a new era of exploitation. Mater. Sci. Forum 560, 1-9.

Zhou Y J, Zhang Y, Wang Y L, and Chen G L (2007) Solid solution alloys of AlCoCrFeNiTix with excellent room-temperature mechanical properties. Appl. Phys. Lett. 90, 181904.

Zhu J M, Fu H M, Zhang H F, Wang A M, Li H, and Hu Z Q (2010) Synthesis and properties of multiprincipal component AlCoCrFeNiSix alloys. Mater. Sci. Eng. A 527, 7210-7214. 